\title{
HAS THE INTERNET ELIMINATED REGIONAL PRICE DIFFERENCES? EVIDENCE FROM THE USED CAR MARKET***
}

BY

MARCO A. HAAN*, HENK-WIM DE BOER**

\section{Summary}

We study the effects of the Internet on regional price differences. Comparing two Dutch regions, we find that before the rise of the Internet, price differences of used cars between those regions amounted to some $11-15 \%$, controlling for mileage, age, fuel type and engine volume. These price differences have completely disappeared after the rise of the Internet, in particular a website that allows consumers to make detailed comparisons between almost all used cars for sale in the Netherlands.

Key words: internet, regional price differences

JEL Code(s): D12, D43, D83, L10

\section{INTRODUCTION}

The effects of the Internet on the competitiveness of markets have been widely discussed, both in the theoretical and the empirical literature (for an overview, see e.g. Bakos 2001). Many studies address the extent to which the Internet has affected price dispersion and/or price levels. Yet, this literature focuses solely on homogeneous products in a given market. In this paper we study the extent to which the Internet has affected price differences of differentiated products between regions.

In our study we focus on used cars. These are highly differentiated products as they differ not only in brand, type, engine volume and accessories, but also in mileage and age making it hard for consumers to find their preferred product and evaluate the options that each individual supplier has on offer. We study the extent to which the Internet has affected prices of used cars.

* Corresponding author: Faculty of Economics and Business, University of Groningen,

P.O.Box 800, 9700 AV Groningen, The Netherlands, e-mail: m.a.haan@rug.nl

** Ministry of Social Affairs and Employment, The Hague, The Netherlands

*** The authors thank two anonymous referees, Peter Kooreman, José Luis Moraga González, Linda Toolsema, Robert Veldman, Bjørn Volkerink, and participants at the 2005 NAKE Research Day, the 2006 EARIE conference, and seminars at the University of Groningen and the Utrecht School of Economics for useful comments. 
In particular, we analyze whether price differences between regions have been affected.

We expect such an effect for the following reason. Consider a consumer that wants to buy a used car, somewhere in the 1990s. She does not have perfect information regarding prices and the exact specifications of the cars that each dealer has on offer. She can look at e.g. newspaper ads, but these only contain relatively little information and take a lot of effort to find and analyze. Ultimately, this consumer has to go to the dealer to obtain crucial information about the car she might be interested in. In such a case, it is likely that prices are higher in regions where there are relatively fewer firms, as search costs for consumers (i.e. the costs involved to be able to evaluate a single product) are higher.

Now suppose that a website is introduced that provides more information about used cars, and allows consumers to compare them much more easily. It now takes much less effort to select cars, check their specifications and see what they look like. Of course, before purchasing a car the consumer still wants to visit the dealer to be able to 'kick the tyres'. But from the comfort of her home she is already able to rule out many more cars than before. The number of firms she has to visit physically to find a good match will be much lower. In other words, search costs will have decreased substantially and will have been virtually equalized between regions. As a result, we expect price differences between the two regions to be much smaller, as it now equally easy for all consumers to become informed.

In this paper we use data from the used car market in two regions in the Netherlands. Arguably, market conditions between these regions differed markedly. In one region, the density of car dealers is much lower, which implies that consumer search costs are higher, and firms have more market power. We find that for a sample collected in the mid 1990s prices are indeed much higher in the region with higher search costs. Nowadays, virtually all used cars that offered by dealers in the Netherlands are listed on the website http://www.autoscout24.nl, including all the characteristics of the car and a picture. Therefore, one would expect regional price differences to be affected. We find that they have completely disappeared.

The remainder of this paper is structured as follows. In the next section, we provide a short survey of related literature that discusses the effects of the Internet on prices and price dispersion. We then explain our methodology. Next, we study used car prices in the Netherlands in the mid-1990s. We describe our data sets and show that, ceteris paribus, car prices in the west of the country were roughly $13 \%$ lower than prices in the north. Then, we study used car prices in the Netherlands as listed on the Internet in 2005. We show that in this data set price differences have been wiped out. The final section discusses alternative explanations for the price convergence that we find. In 
particular, we look at some anecdotal evidence regarding the price dealers pay for trade-ins. Section 7 concludes.

\section{RELATED LITERATURE}

It has often been argued that the Internet makes it easier for consumers to compare prices online. In other words, the Internet has lowered search costs for consumers. Lower search costs in turn imply more competitive markets. A substantial body of theory predicts that lower search costs will lead to less dispersion of prices. See e.g. Burdett and Judd (1983), Diamond (1987), Rob (1985), Reinganum (1979), or Stigler (1961).

Yet, many empirical studies refute the hypothesis that price dispersion decreases due to the Internet. Brynjolfsson and Smith (2000) find substantial dispersion for prices of books and CDs on the Internet, to an extent that is roughly comparable to that in offline markets. Clay et al. (2003) report similar findings for the online book market. Chevalier and Goolsbee (2003) find that book prices are much more variable online than in retail stores. Clemons et al. (2002) find substantial differences in the prices of online travel agents. Scholten and Smith (2002) find that price dispersion in online markets in 2000 is at least as high price dispersion in retail markets in 1976. In the most comprehensive study to date, Baye et al. (2004) find online price dispersion for more than 1,000 consumer electronics products. Thus, although it is often argued that the Internet lowers consumer search costs, empirical studies do not find that this indeed lowers price dispersion, as predicted by theory.

The theoretical literature also predicts that lower search costs will lead to lower prices, see e.g. Anderson and Renault (1999). Empirical studies do suggest that the Internet has indeed lowered prices. Admittedly, early studies still suggested that prices were higher online than in retail stores. Lee (1998) finds higher prices for used cars on the internet. Bailey (1998) finds the same result for books, CDs and software. But more recent work does find a beneficial effect of the Internet. Brynjolfsson and Smith (2000) find that, for books and CDs, prices on the Internet are 9-16\% lower than prices in conventional outlets. Morton et al. (2001) find that consumers that use an online car referral service pay on average $2 \%$ less for a new car. Brown and Goolsbee (2002) find that Internet comparison sites have reduced prices for life insurance by $8-15 \%$.

\section{METHODOLOGY}

What all the empirical studies cites in "Related Literature" have in common, is that they look at the effect of the Internet on prices of homogeneous products in a single market. The fact that the literature focuses on homogenous products may not be too surprising. As differentiated products are by 
definition different, it is hard to compare their prices at one point in time, let alone to evaluate how these price differences have evolved over time. In this paper, we circumvent these problems. To control for the differences between products at one point in time we effectively do a hedonic regression, controlling for observable characteristics. To evaluate whether price differences have changed due to the Internet, we look at two regions that arguably differed in the amount of search costs that consumers had to incur in the 1990s, but where those search cost differences have become much smaller due to the Internet. We thus collect data for used cars in two different regions that were offered in the mid 1990s (before the Internet) and in 2005 (after the Internet).

We will thus not study how price dispersion has evolved in the two regions that we consider, different from what most of the literature on homogenous products does. To study price dispersion, one truly needs homogeneous products. With differentiated products, which is what we have, the only option would be to look at the dispersion of the residuals of the hedonic price regression. But it is unclear whether that truly measures price dispersion or merely the goodness-of-fit of the hedonic regression.

The first region we use is the North, for our purposes defined as the region within a radius of $50 \mathrm{~km}$ (some 30 miles) around Groningen, the largest city in the area, with some 170,000 inhabitants at the time. The second region is the West, for our purposes defined as the region within a radius of $50 \mathrm{~km}$ around the Hague, a city with some 450,000 inhabitants. The distance between Groningen and the Hague is some 230 kilometers by road. ${ }^{1}$

The North and West regions differ markedly. The West is characterized by high economic activity and a high population density, at 990 inhabitants per square kilometer in 1994. The North is relatively poor, largely rural, and only has 192 inhabitants per square kilometer. ${ }^{2}$ The density of car dealers is also much lower in the North than it is in the West. In 2005, the province of Groningen (which includes the city of Groningen) had one registered car dealer per $27.2 \mathrm{~km}^{2}$. The province of Zuid-Holland (which includes the city of The Hague) had one for each $4.8 \mathrm{~km}^{2}{ }^{3}$ This implies that to compare prices and characteristics of used cars at a given number of dealers, consumers in the North have to travel much more than consumers in the West. In that sense, search costs in the North are higher than those in the West. Therefore, one can expect firms in the North to have more market power and set higher prices than those in the West.

1 Distance determined using car navigation software.

2 Data obtained from Statistics Netherlands, http://www.cbs.nl.

3 Data on dealerships from BOVAG, the Dutch trade association of car dealers and related firms. As of May 5, 2005, their website, http://www.bovag.nl, lists 598 dealers in Zuid-Holland, and 109 in Groningen. Data on province size from Statistics Netherlands, http://www.cbs.nl. 
To assess the differences in used car prices between the two regions, we ideally would like to compare the price of exact same used car being offered in the two regions. Obviously, that is not feasible. The closest we can get to that ideal experiment is by comparing prices of used cars of the same brand and make, while controlling for observable characteristics. At each point in time, we thus explain the log of price of cars in our sample from observable characteristics and a dummy variable that reflects the region whether the car is offered in West. To assess how regional price differences have developed over time, we simply do this exercise twice, and compare the estimates of the coefficient of the regional dummy.

Our approach is close in spirit to a difference in differences estimator (DD; see e.g. Ashenfelter and Card 1985) with the treatment being the introduction of the Internet. In such an approach, however, data from before and after the treatment is pooled and a single regression is run using a treatment dummy, a group (in our case: regional) dummy, and the interaction of the two. Thus, with a DD estimator, we would estimate:

$$
\ln \mathrm{P}_{\mathrm{i}}=\beta_{1} \mathrm{X}_{\mathrm{i}}+\beta_{2} \mathrm{~T}_{\mathrm{i}}+\beta_{3} \mathrm{R}_{\mathrm{i}}+\beta_{4}\left(\mathrm{~T}_{\mathrm{i}} * \mathrm{R}_{\mathrm{i}}\right)+\varepsilon_{\mathrm{i}}
$$

with $\mathrm{X}_{\mathrm{i}}$ a vector of observable characteristics, $\mathrm{T}_{\mathrm{i}}$ a treatment dummy that reflects whether this car was sold in 2005, and $R_{i}$ a regional dummy that reflects whether the car was sold in West. Testing whether regional price differences have not changed then boils down to testing whether $\beta_{4}=0$, whereas testing whether regional price differences have disappeared would boil down to testing whether $\beta_{3}=-\beta_{4}$.

Pooling the data in this manner would however imply the restriction that cars and the demand for them have not changed between the mid 1990s and 2005. More precisely, it would imply that the coefficient $\beta_{1}$ is time independent. In other words, it would impose that, say, a 3-year old Volvo 440 that has run $50,000 \mathrm{~km}$ would fetch the same price in 1995 as a 3-year old Volvo $\mathrm{S} 40$ that has run $50,000 \mathrm{~km}$ would fetch in 2005 . We see little reason as to why that would be the case. We therefore estimate the following two equations separately on the two subsamples

$$
\begin{aligned}
& \ln \mathrm{P}_{\mathrm{i} 1}=\beta_{11} \mathrm{X}_{\mathrm{i} 1}+\beta_{31} \mathrm{R}_{\mathrm{i} 1}+\varepsilon_{\mathrm{i} 1} \\
& \ln \mathrm{P}_{\mathrm{i} 2}=\beta_{12} \mathrm{X}_{\mathrm{i} 2}+\beta_{32} \mathrm{R}_{\mathrm{i} 2}+\varepsilon_{\mathrm{i} 2}
\end{aligned}
$$

where the additional subscripts 1 and 2 reflect whether the car is observed in the mid 1990s or in 2005, respectively. Testing whether regional price differences have not changed now boils down to testing whether $\beta_{31}=\beta_{32}$, whereas testing whether regional price differences have disappeared boils down to testing whether $\beta_{32}=0$. 
We expect to find that prices in West were lower in the mid-1990s, due to lower search costs. Hence $\beta_{31}<0$. Moreover, we expect regional price differences to have diminished $\left(\beta_{31}<\beta_{32}\right)$, or even disappeared $\left(\beta_{32}=0\right)$.

\section{USED CAR PRICES BEFORE THE INTERNET}

For the period 1994-1996 we collected data on two types of cars. We collected data manually from newspaper advertisements by certified brand dealers. A large part of Dutch used car transactions go through brand dealers, although there are some private transactions between individuals as well, in particular for older cars. Transactions through dealers often involve trade-ins. Of course, we only observe ask prices. Prices could be negotiable, although in practice negotiations usually seem to concern the price the dealer is willing to pay for the trade-in. We do not believe that our results are influenced by the fact that we observe ask prices rather than transaction prices. We will return to this issue in Sect. 6.

To limit the extent of heterogeneity in our data set, we restrict attention to one type of car in both samples that we use. In the first sample, we study the Citroen BX, a mid-range car that was highly successful in the 1990s, and thus yields a relatively high number of observations. For the same reason, we have chosen the Volvo 440 in our second sample. Data for the North are collected from ads in Het Nieuwsblad van het Noorden,${ }^{4}$ the largest regional newspaper in the area. Data from the West are obtained from ads in De Telegraaf, the largest national newspaper and the most important source for information on used cars in West at the time. We use ads from the period 1994-1996, long before there were any price comparison sites for used cars on the Internet. We correct for inflation using annual CPI data, using 2004 euro prices. ${ }^{5}$ We restrict attention to a limited set of car dealers to try to avoid biases due to data selection effects.

Sample statistics are given in Table 1. Note that in sample 1, the North and the West are very much comparable, although the cars advertised in the West are on average slightly younger, have slightly lower mileage, and have a higher engine volume than those advertised in the North. For sample 2, there is an even closer match between the descriptive statistics of the two regions.

We explain the natural logarithm of the advertised price of a car from the car's age (in years), its mileage (in units of $10,000 \mathrm{~km}$ ), engine volume (in liters), and dummies for the type of fuel. Following Kooreman and Haan (2006), we measure age in calendar years, and include a dummy for cars that

4 This newspaper is currently known as 'Dagblad van het Noorden'.

5 We use annual rather than monthly CPI data as Kooreman and Haan (2006) find that consumers also evaluate used cars on the basis of their age in calendar years rather than their actual age in months. 
TABLE 1 - SAMPLES 1 AND 2: SAMPLE STATISTICS

\begin{tabular}{|c|c|c|c|c|}
\hline \multirow[t]{2}{*}{ Variable } & \multicolumn{2}{|c|}{ Citroen BX } & \multicolumn{2}{|c|}{ Volvo 440} \\
\hline & North & West & North & West \\
\hline \# Observations & 118 & 165 & 105 & 92 \\
\hline \multicolumn{5}{|l|}{ Price } \\
\hline Minimum & 1748 & 2856 & 9203 & 7213 \\
\hline Maximum & 17126 & 24259 & 23674 & 25232 \\
\hline Mean & 8823 & 9650 & 17153 & 14714 \\
\hline Standard deviation & 3511 & 3860 & 3274 & 4438 \\
\hline \multicolumn{5}{|l|}{ Transmission } \\
\hline Manual & & & $94 \%$ & $91 \%$ \\
\hline Automatic & & & $6 \%$ & $9 \%$ \\
\hline \multicolumn{5}{|l|}{ Fuel } \\
\hline Diesel & $8 \%$ & $18 \%$ & & \\
\hline Gas & $14 \%$ & $12 \%$ & $11 \%$ & $17 \%$ \\
\hline Petrol & $79 \%$ & $70 \%$ & $89 \%$ & $83 \%$ \\
\hline \multicolumn{5}{|l|}{ Engine volume } \\
\hline Mean & 1,553 & 1,658 & 1,818 & 1,823 \\
\hline Standard deviation & 188 & 208 & 81 & 98 \\
\hline \multicolumn{5}{|l|}{ Age (in years) } \\
\hline Minimum & 2 & 1 & 1 & 1 \\
\hline Maximum & 11 & 9 & 7 & 7 \\
\hline Mean & 5.11 & 4.43 & 3.11 & 3.08 \\
\hline Standard deviation & 1.91 & 1.62 & 1.23 & 1.38 \\
\hline \multicolumn{5}{|l|}{ Kilometers driven } \\
\hline Minimum & 18,000 & 25 & 3,500 & 1,250 \\
\hline Maximum & 190,000 & 200,000 & 179,000 & 170,000 \\
\hline Mean & 95,030 & 89,397 & 43,729 & 51,539 \\
\hline Standard deviation & 42,326 & 43,672 & 34,629 & 39,290 \\
\hline
\end{tabular}

have run over $100,000 \mathrm{~km} .{ }^{6}$ We also include a dummy that equals 1 if the car is advertised in West, and 0 if it is advertised in North.

Obviously, we expect that mileage and the age of a car have a negative effect on its price. Larger engines should command higher prices. Moreover, as explained above, we expect that prices in West are lower than those in North. Hence, we expect the region dummy to be negative and significant. Throughout this paper, we use ordinary least squares. Regression results for sample 1 and 2 are given in Table 2.

The second column of Table 2 shows that the coefficients for mileage and age have the expected sign and are highly significant. Nevertheless, it is 
TABLE 2 - ESTIMATION RESULTS SAMPLES 1 AND 2

\begin{tabular}{lll}
\hline & Citroen BX & Volvo 440 \\
\hline Constant & $9.26(88.56)^{* *}$ & $8.43(53.28)^{* *}$ \\
\# Kilometers driven & $-0.030(-6.10)^{* *}$ & $-0.037(-8.39)^{* *}$ \\
$100,000 \mathrm{~km}$ & $-0.101(-2.73)^{+}$ & $0.002(0.06)$ \\
Age in years & $-0.153(-20.53)^{* *}$ & $-0.072(-8.92)^{* *}$ \\
Engine volume & $0.575(9.39)^{* *}$ & $0.928(11.35)^{* *}$ \\
Diesel & $-0.021(-0.56)$ & \\
LPG & $-0.052(-1.57)$ & $0.059(2.57)$ \\
Automatic & & $0.089(3.45)^{* *}$ \\
Region West & $-0.120(-5.57)^{* *}$ & $-0.166(-12.49)^{* *}$ \\
$n$ & 283 & 197 \\
Adjusted $R^{2}$ & 0.846 & 0.886 \\
F-statistic & 222.28 & 219.12 \\
\hline
\end{tabular}

(Dependent variable: $\ln$ (price); $t$-values in parentheses)

** Significant at the $1 \%$-level.

* Significant at the $5 \%$-level.

+ Significant at the $10 \%$-level.

problematic to directly interpret these coefficients, as there is obviously a strong correlation between age and mileage. For the purposes of our paper, this is immaterial as we are not interested in these coefficients, but only in the coefficient of the region dummy. The high value of the adjusted $R^{2}$ suggests that a large portion of the variation in used car prices can be explained by the variables included in our regression. The F-statistic indicates that the joint hypothesis that all coefficients equal zero, is strongly rejected. Dummies for diesel and LPG are insignificant and have the wrong sign. This may be a selection effect. On average, cars equipped with diesel or LPG will have higher mileage per year, as these technologies have a higher fixed costs but lower marginal costs for the owner of the car. Therefore, our dummies for diesel and LPG may pick up some of the effects that should be attributed to mileage. Most interestingly, our region dummy is highly significant, and shows a strong effect. Ceteris paribus, in the 1990s, used Citroen BXs that are sold in West are over $11 \%$ cheaper than used cars sold in North. Search costs are much lower in West, which implies that prices are lower as well, confirming Anderson and Renault (1999).

For the second sample, we do the same analysis. In this sample we do not have diesel cars, but we do have cars with automatic transmission. Therefore, we use an automatic transmission dummy rather than a diesel dummy. The last column of Table 2 shows that all coefficients are highly significant and have the expected sign. The region effect is even stronger than that in the 
previous sample: we find that used Volvos are approximately $15 \%$ cheaper in the West.

For both samples, we have tried a host of other specifications by dropping dummies, including other dummies, eliminating outliers, and considering a subsample of non-diesel cars. Yet, all these specifications give a value for the region dummy that is comparable to that reported in Table 2.

\section{USED CAR PRICES IN THE NETHERLANDS AFTER THE INTERNET}

For our second analysis, we obtained data from http://www.autoscout24.nl in 2005. As much as possible, we have restricted ourselves to cars offered by the car dealers that were also in our mid 1990s sample. Again, we look at two types of cars, and use the same empirical strategy as in the previous section: for each type of car, we explain prices from characteristics such as age and mileage, plus a dummy for the region in which the car was sold. The coefficient of the region dummy reflects the price difference between the two regions.

The website http://www.autoonline.nl was launched on April 1, 2000. In 2005, its name changed to http://www.autoscout24.nl. The site is set up by RDC and Autodata. These are centers that collect data on transactions and the supply of used cars at all registered car dealers in the Netherlands. Note that the website merely lists these cars, and offers several selection facilities. Cars can be selected on the basis of brand, type, color, price, mileage, age, and location of the dealer. Consumers still need to go to the dealer to buy the car, without having to reveal that they saw the car listed on the Internet.

Note that http://www.autoscout24.nl is not a referral site, as is the case for most websites in the US offering used cars (see e.g. Morton et al. 2001). Many studies on price dispersion compare products that are offered online with products that are offered in conventional retail outlets. For the used car market in the Netherlands, such a distinction cannot be drawn. Cars that are offered in outlets of certified dealers, are also listed on the Internet, and vice versa.

Searching for cars on the Internet is much easier than searching for cars using newspaper ads. For example, relatively few dealers list all relevant car characteristics in their newspaper ads. This is exactly the reason that it was much harder for us to collect data from newspaper ads than it was to collect data from the internet. Also, cars that are advertised on http://www. autoscout24.nl almost always include a picture of the car, and many more details than are ever reported in newspaper ads. Third, consumers that search on the Internet have the option to specify a large number of search criteria, something that obviously is not possible with newspaper ads.

In our newspaper samples, we exclusively used data on the Citroen BX and Volvo 440, respectively. Ideally, we would like to use the same cars for our 
TABLE 3 - SAMPLES 3 AND 4: SAMPLE STATISTICS

\begin{tabular}{|c|c|c|c|c|}
\hline \multirow[b]{2}{*}{ Variable } & \multicolumn{2}{|c|}{ Citroen Xsara Picasso } & \multicolumn{2}{|c|}{ Volvo S40 } \\
\hline & North & West & North & West \\
\hline \# Observations & 112 & 111 & 123 & 153 \\
\hline \multicolumn{5}{|l|}{ Price } \\
\hline Minimum & 11750 & 8450 & 4750 & 5012 \\
\hline Maximum & 24950 & 26950 & 34950 & 40449 \\
\hline Mean & 17588 & 16619 & 14200 & 16657 \\
\hline Standard deviation & 3568 & 3336 & 7390 & 7182 \\
\hline \multicolumn{5}{|l|}{ Transmission } \\
\hline Manual & & & $95 \%$ & $89 \%$ \\
\hline Automatic & & & $5 \%$ & $11 \%$ \\
\hline \multicolumn{5}{|l|}{ Fuel } \\
\hline Diesel & $27 \%$ & $13 \%$ & $25 \%$ & $14 \%$ \\
\hline Gas & $9 \%$ & $2 \%$ & & \\
\hline Petrol & $64 \%$ & $86 \%$ & $75 \%$ & $86 \%$ \\
\hline \multicolumn{5}{|l|}{ Engine volume } \\
\hline Mean & 1,823 & 1,784 & 1,872 & 1,876 \\
\hline Standard deviation & 128 & 98 & 142 & 158 \\
\hline \multicolumn{5}{|l|}{ Age (in years) } \\
\hline Minimum & 1 & 1 & 1 & 1 \\
\hline Maximum & 5 & 5 & 10 & 9 \\
\hline Mean & 2.82 & 3.43 & 5.82 & 4.59 \\
\hline Standard deviation & 1.46 & 1.45 & & \\
\hline \multicolumn{5}{|l|}{ Kilometers driven } \\
\hline Minimum & 2,607 & 2,500 & 4,000 & 3,000 \\
\hline Maximum & 198,015 & 138,171 & 234,204 & 245,600 \\
\hline Mean & 89,485 & 52,601 & 100,063 & 80,629 \\
\hline Standard deviation & 50,035 & 34,958 & 54,866 & 51,786 \\
\hline
\end{tabular}

online samples. That, however, is not possible, as these cars are no longer produced. We have therefore chosen to analyze their successors, the Citroen Xsara Picasso and the Volvo S40. Again, we use dealers from the North and West region, as defined earlier. As much as possible, we have used the same dealers as in our newspaper samples. Yet, for our online samples, we needed more dealers, as we collected the data from a shorter time period. Since we had no automated access to the data, the information was secured manually by separately clicking on each observation and storing it into a data file. Table 3 gives the sample statistics.

Table 3 shows that on average, Picassos in West are somewhat older, but Volvos are somewhat younger than in North. Cars in West have lower mileage. Moreover, in West we have less cars with LPG or diesel. 
TABLE 4 - ESTIMATION RESULTS SAMPLES 3 AND 4

\begin{tabular}{lll}
\hline & Citroen Xsara Picasso & Volvo S40 \\
\hline Constant & $9.80(85.14)^{* *}$ & $9.67(87.86)^{* *}$ \\
\# Kilometers driven & $-0.022(-6.49)^{* *}$ & $-0.019(-5.42)^{* *}$ \\
$100,000 \mathrm{~km}$ & $-0.024(-1.03)$ & $-0.011(-0.39)$ \\
Age in years & $-0.073(-10.24)^{* *}$ & $-0.133(-24.74)^{* *}$ \\
Engine volume & $0.146(2.28)^{*}$ & $0.377(6.92)^{* *}$ \\
Diesel & $0.099(5.07)^{* *}$ & $0.069(3.07)^{* *}$ \\
LPG & $-0.026(-0.85)$ & $0.100(3.43)^{* *}$ \\
Automatic & & $-0.007(-0.41)$ \\
Region West & $0.010(0.76)$ & 276 \\
$n$ & 224 & 0.929 \\
adjusted $R^{2}$ & 0.841 & 513.64 \\
F-statistic & 168.93 & \\
\hline
\end{tabular}

(Dependent variable: $\ln$ (price); $t$-values in parentheses)

** Significant at the $1 \%$-level.

* Significant at the 5\%-level.

We do the same exercise as in the previous section, explaining the natural logarithm of the advertised price of a car from the car's age, mileage, engine volume, dummies for the type of fuel, a dummy for having passed the $100,000 \mathrm{~km}$ mark and a region dummy. The results are reported in Table 4.

Again, in the Citroen sample, the LPG dummy is not significant, while it is in the Volvo sample. All other car-related variables are significant and have the expected sign. Most interesting is the coefficient of the region dummy. In the newspaper sample, cars sold in West carried a discount of 11 and $15 \%$ respectively. Now, there is a small premium for Citroens of $1 \%$, but this is not significant. For our Volvos, we find a discount for the Western region which is smaller than $1 \%$, and insignificant. Hence, the Internet indeed seems to have eliminated regional price differences on the used car market in the Netherlands.

\section{ALTERNATIVE EXPLANATIONS}

In the previous sections, we established that regional price differences on the used car market in the Netherlands have disappeared between 1994 and 2005. The most natural explanation is the introduction of the Internet and, in particular, the introduction of a comparison site for used cars. Before the Internet, search costs in North were much higher than those in West, as the dealer density is much lower. With the Internet, search costs are equal; by using the 
Internet, it is just as costly to find characteristics and prices for cars that are for sale in North as it is for cars that are for sale in West.

There could be other explanations as to why regional price differences have disappeared. First, there may have been a change in market structure between the mid 1990s and 2005. Second, our results may be explained by systematic differences in the prices that dealers pay for trade-ins. Third, price equalization may be due to increased arbitrage by car dealers facilitated by the internet, rather than by a decrease in consumer search costs. We consider each of these alternative explanations in turn. In each case, we conclude that it is unlikely to explain our results.

First, the market structure of the Dutch used car market may have changed. Again, to explain our results, we would need a change in market structure that is substantially different in North than it is in West. For example, suppose that the period 1995-2005 saw many mergers between car dealers in West, and no such mergers in North. Then, it could be true that the market power of the average dealer in 1995 was much higher in North than in West, while that difference has disappeared by 2005 . Unfortunately, we do not have information on the number of registered car dealers in 1995. However, Statistics Netherlands does provide information on the number of firms involved in trade and repair of cars. In the north of the Netherlands, the number of such firms has increased from 1430 in 1995 to 1755 in 2005, an increase of $23 \%$. In the west of the Netherlands, the number of such firms has increased from 5425 in 1995 to 5590 in 2005, an increase of $3 \%{ }^{7}$ While this may explain part of the change in the regional price differential, it is hard to see why it would imply that prices have exactly converged. Even after the increase, the number of firms involved in trade and repair of cars still stood at only 1 per $6.5 \mathrm{~km}^{2}$ in North, but at 1 per $2.1 \mathrm{~km}^{2}$ in West. Moreover, as we reported earlier, the density of car dealers in North in 2005 is still substantially lower than that in West, with one registered car dealer per $27.2 \mathrm{~km}^{2}$ and one per $4.8 \mathrm{~km}^{2}$, respectively.

Second, the price that dealers pay for trade-ins may have changed between 1995 and 2005. More specifically, although car dealers in North now ask the same price for a used car as their colleagues in West, the prices they pay for trade-ins may have diverged. If that were the case, then the net price that a consumer pays who trades in his or her car, may still be substantially higher in North. Of course, it is very hard to evaluate whether this really is the case, as we cannot possibly observe the prices that are paid for trade-ins. Yet, the

7 See http://www.cbs.nl. The numbers reported here concern the number of branches active in SBI'93 category 50104, which is 'Trade and Repair of Cars', in the areas that are denoted by Statistics Netherlands as 'north' and 'west'. Note that these numbers refer to the number of branches, not the number of firms. Also note that our definitions of 'North' and 'West' do not exactly coincide with those of Statistics Netherlands. 
Dutch Automobile Association (ANWB) does provide some anecdotal evidence.

In the fall of 2005, ANWB Kampioen, the monthly magazine of the Dutch Automobile Association, anonymously offered a single used car to 50 different car dealers throughout the country (see ANWB 2005). It sampled ten dealers in each of five regions: North, East, Center, West and South. ${ }^{8}$ Differences between the prices that individual dealers offered were substantial, but the regional price differences much less so. In particular, the price offered by dealers in North was 3,992 euro, while that in West was 3,950 euro, a difference of just $1 \%$. This suggests that not only the posted prices for used cars have converged, but also that the prices that dealers offer for trade-ins do not systematically differ among regions. ${ }^{9}$

Third, the disappearance of regional price differences may also be due to arbitrage by car dealers, rather than lower consumer search costs. We do not believe this to be the case however, as before 1995 car dealers already had access to a national database of all used cars offered by certified dealers so we would also expect such arbitrage to occur in the mid 1990s. Anyhow, even if arbitrage would be the explanation, this would not affect our main conclusion that the Internet has eliminated regional price differences for used cars in the Netherlands.

\section{CONCLUSION}

In this paper, we studied the effects of the Internet on regional price differences. Comparing two regions that arguably differ in their search costs, we find that before the rise of the Internet, price differences of used cars between those regions amounted to some $11 \%$ for Citroens and even $15 \%$ for Volvos, controlling for mileage, age, fuel type and engine volume. After the rise of the Internet, and in particular a price comparison site that includes all cars offered through certified dealers in the Netherlands, these regional price differences seem to have completely disappeared.

Open Access This article is distributed under the terms of the Creative Commons Attribution Noncommercial License which permits any noncommercial use, distrib-

8 Note however that the ANWB's definitions of 'North' and 'West' do not exactly coincide with ours.

9 Although suggestive, this of course does not fully rule out the possibility that trade-ins are part of the explanation: it may well be that in 1995, dealers in the North asked higher prices while also offering higher trade-in prices (or discounts in the absence of a trade-in). Under the influence of the internet price transparency, both prices may have fallen to the level in the West, without affecting net transaction prices paid. Thanks to an anonymous referee for pointing this out. 
ution, and reproduction in any medium, provided the original author(s) and source are credited.

\section{REFERENCES}

Anderson, S. and R. Renault (1999), 'Pricing, Product Diversity, and Search Costs: A BertrandChamberlin-Diamond Model', RAND Journal of Economics, 30, pp. 719-735.

ANWB (2005), Auto inruilen? Shoppen loont!, [Trading in your car? Shopping around pays off!], ANWB Kampioen, September (online at http://www.kampioen.nl/published/kmp/content/ binairebestanden/K11+2005+auto+inruilen-115775_115787.pdf).

Ashenfelter, O. and D. Card (1985), 'Using the Longitudinal Structure of Earnings to Estimate the Effect of Training Programs'. The Review of Economics and Statistics, 67(4), pp. 648-660.

Bailey, J.P. (1998), Intermediation and Electronic Markets: Aggregation and Pricing in Internet Commerce, Ph.D. Thesis, Technology, Management and Policy, MIT.

Bakos, Y. (2001), 'The Emerging Landscape for Retail E-Commerce', Journal of Economic Perspectives, 15(1), pp. 69-80.

Baye, M.R., J. Morgan and P. Scholten (2004), 'Price Dispersion in the Small and in the Large: Evidence from an Internet Price Comparison Site', Journal of Industrial Economics, 52(4), pp. 463-497.

Brown, J.R. and A. Goolsbee (2002), 'Does the Internet Make Markets More Competitive? Evidence from the Life Insurance Industry'., Journal of Political Economy, 110(3), pp. 481-507.

Brynjolfsson, E. and M.D. Smith (2000), 'Frictionless Commerce? A Comparison of Internet and Conventional Retailers', Management Science, 46(4), pp. 563-585.

Burdett, K. and K.L. Judd (1983), 'Equilibrium Price Dispersion', Econometrica, 51(4), pp. 955-970.

Chevalier, J. and A. Goolsbee (2003), 'Measuring Prices and Price Competition Online: Amazon.com and BarnesandNoble.com', Quantitative Marketing and Economics, 1, pp. 203-222.

Clay, K., R. Krishnan and E. Wolff (2003), 'Retail Strategies on the Web: Price and Non-Price Competition in the Online Book Industry', Journal of Industrial Economics, 49(4), pp. 521-539.

Clemons, E., I. Hann and L. Hitt (2002), 'Price Dispersion and Differentiation in Online Travel: An Empirical Investigation', Management Science, 48(4), pp. 534-549.

Diamond, P.A. (1987), 'Consumer Differences and Prices in a Search Model', Quarterly Journal of Economics, 102(2), pp. 429-436.

Kooreman, P. and M.A. Haan (2006), 'Price Anomalies in the Used Car Market', De Economist, 154(1), pp. 41-62.

Lee, H.G. (1998), 'Do Electronic Marketplaces Lower the Price of Goods?', Communications of the $A C M, 41(1)$, pp. 73-80.

Morton, F.S., F. Zettelmeyer and J. Silva-Risso (2001), 'Internet Car Retailing', Journal of Industrial Economics, 49(4), pp. 501-519.

Reinganum, J.F. (1979), 'A Simple Model of Equilibrium Price Dispersion', Review of Economic Studies, 52(3), pp. 487-504.

Rob, R. (1985), 'Equilibrium Price Dispersion', Review of Economic Studies, 52(3), pp. 487-504.

Scholten, P. and S.A. Smith (2002), 'Price Dispersion Then and Now: Evidence from Retail and E-tail Markets'. in: M.R. Baye, (ed.), Advances in Applied Microeconomics, vol. 11, pp. 63-88.

Stigler, G.J. (1961), 'The Economics of Information', Journal of Political Economy, 69(3), pp. 213-225. 